\title{
Dietary comparison of two Hawaiian monk seal populations: the role of diet as a driver of divergent population trends
}

\author{
M. K. Cahoon ${ }^{1, *}$, C. L. Littnan' ${ }^{2}$ K. Longenecker ${ }^{3}$, J. R. Carpenter ${ }^{4}$ \\ ${ }^{1}$ Joint Institute for Marine and Atmospheric Research, 1000 Pope Road, Honolulu, Hawaii 96822, USA \\ ${ }^{2}$ Pacific Islands Fisheries Science Center, National Marine Fisheries Service, NOAA, 1601 Kapiolani Boulevard, Honolulu, \\ Hawaii 96814, USA \\ ${ }^{3}$ Bishop Museum, 1525 Bernice Street, Honolulu, Hawaii 96817, USA \\ ${ }^{4}$ Department of Human Nutrition, Food and Animal Sciences, University of Hawaii at Manoa, 1955 East West Road, \\ Honolulu, Hawaii 96822, USA
}

\begin{abstract}
Divergent trends in population abundance of Endangered Hawaiian monk seals Monachus schauinslandi are apparent between the northwestern Hawaiian Islands (NWHI) and the main Hawaiian Islands (MHI). The smaller, recently established MHI seal population is increasing, exhibits higher juvenile survival, and seals appear to be in better condition overall relative to seals in the NWHI. Using traditional dietary analysis we characterize the diet of MHI monk seals for the first time and examine the hypothesis that diet and prey availability may be driving these regional trends. Prey remains from feces and regurgitates $(n=120)$ were identified to the lowest possible taxonomic level and compared with results from NWHI historical data. The most common prey taxa, by percent frequency of occurrence, were Balistidae (48.3\%), Crustacea $(37.5 \%)$, Acanthuridae (32.5\%), Muraenidae (30.8\%), Serranidae $(20.8 \%)$, Cephalopoda $(18.3 \%)$, Holocentridae $(17.5 \%)$, Labridae $(16.7 \%)$, and Scaridae $(10.8 \%)$. Results indicate that MHI and NWHI seals eat similar diets; however, an incongruity in body conditions of seals between regions indicates a possible difference in intra- or inter-specific competition, prey availability, and quality. Further research assessing foraging behavior and habitat use would aid in identifying the regional differences observed.
\end{abstract}

KEY WORDS: Monachus schauinslandi $\cdot$ Fecal prey remains $\cdot$ Diet assessment $\cdot$ Hawaiian Islands

\section{INTRODUCTION}

The endemic, endangered Hawaiian monk seal Monachus schauinslandi is presently declining at a rate of about $4.5 \%$ per annum, with a population currently numbering 1161 seals (Carretta et al. 2010). The population occurs in 2 distinct regions: the northwestern Hawaiian Islands (NWHI) and the main Hawaiian Islands (MHI) (Fig. 1), and a distinct difference in population trajectories is seen between these areas. Although NWHI abundance is decreasing, the smaller, recently established subpopulation of approximately 150 uniquely identified seals in the MHI is increasing (Baker \& Johanos 2004, Baker et al. 2011, T. Wurth pers. comm., 5 November 2012).

Food limitation is considered a primary threat to juvenile Hawaiian monk seal survival in the NWHI as evidenced by poor body condition and emaciation (Craig \& Ragen 1999, Parrish et al. 2005, Stewart et al. 2006). Conversely, in the MHI, seal pups attain greater weights and lengths at weaning (Baker \& Johanos 2004), juveniles experience higher survival 


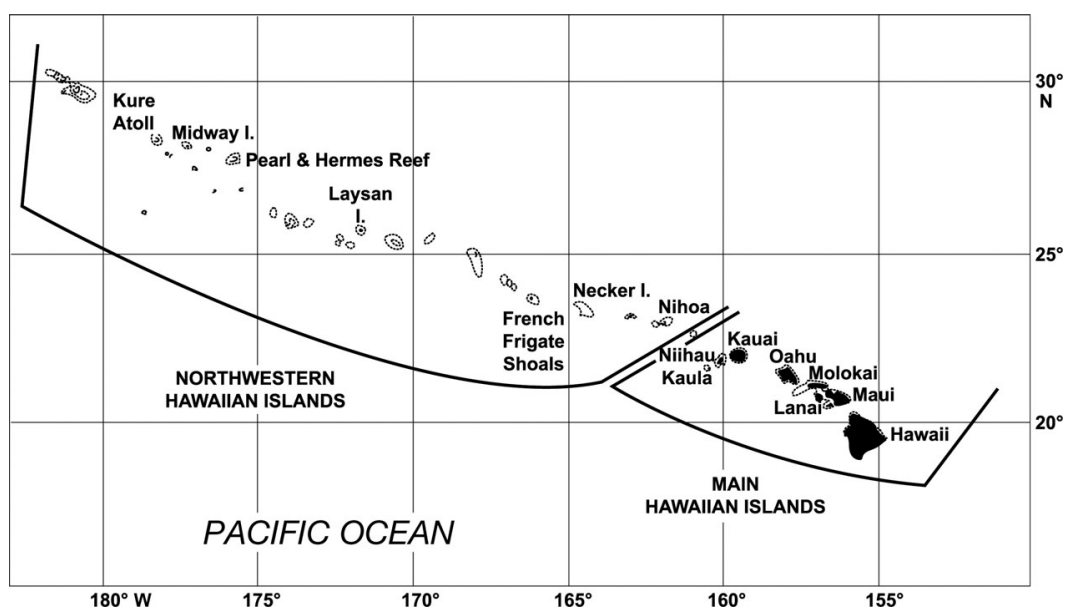

Fig. 1. Distribution of the Hawaiian monk seal Monachus schauinslandi throughout the Hawaiian Archipelago morphological examination of prey remains found in fecal and regurgitate samples to describe the diet of $\mathrm{MHI}$ monk seals for the first time. We then used this information to compare 2 competing hypotheses to try to resolve factors that may be influencing regional monk seal population trends. Specifically, we wanted to determine if (1) MHI and NWHI monk seals eat distinct diets and the former diet is more conducive to body growth and population increase, or (2) MHI and NWHI monk seals eat similar diets, but the MHI seals obtain the same prey with greater efficiency and therefore thrive. rates $(77 \%$ survival from weaning to first year in the MHI vs. 42 to $52 \%$ in the NWHI), and all age and sex classes appear in better condition than their conspecifics in the NWHI (Baker et al. 2011). These trends indicate that MHI seals are more successful at acquiring sufficient resources to thrive relative to their conspecifics in the NWHI. Several hypotheses have been proposed as to why this may be, including intra- and inter-specific competition (Baker \& Johanos 2004, Parrish et al. 2008, Baker et al. 2011); differences in prey type, abundance, or quality (Craig \& Ragen 1999, Friedlander \& DeMartini 2002, Parrish et al. 2005); accessibility and effort required to acquire food (Parrish et al. 2005, Cahoon 2011, Curtice et al. 2011); or a combination of these and other factors.

Our current understanding of NWHI monk seal diet is that seals are opportunistic feeders, targeting a number of benthic and demersal prey, with a diet consisting of a variety of fishes, cephalopods, and crustaceans (Rice 1964, MacDonald 1982, GoodmanLowe 1998, Parrish et al. 2000, Longenecker et al. 2006). It was once thought that the majority of prey were reef-associated (Goodman-Lowe 1998); however, new data show that a proportion of prey also include deep-water species (Iverson et al. 2010) and those associated with sandy habitats (Parrish et al. 2005, Longenecker 2010).

In contrast to the broadly studied diet of NWHI seals, nothing has been published on the diet of MHI seals. But understanding the diet and ecology of this growing population is critical to understand the mechanism influencing population trends, assess overlap and competition with fisheries in the region, and manage the species into the future. We used

\section{MATERIALS AND METHODS}

\section{Sample collection}

Between 2000 and 2009, fecal and regurgitate samples (fresh and old) from monk seals were collected opportunistically year-round on beaches throughout the MHI (Ni'ihau, Kaua'i, O’ahu, Moloka'i, Maui, and Hawai'i Islands) (Fig. 1). No samples were collected at Kaho'olawe or Lāna'i Islands. Opportunistic collection allowed for random sampling and resulted in the collection of samples from known and unknown individuals. Known individuals were from a wide range of age and sex classes. Samples were collected according to standard protocols (National Marine Fisheries Service 2010).

\section{Fecal and regurgitate prey remains}

Anatomical structures from fish (e.g. otoliths, jaw and skull bones, vertebrae, and scales), cephalopods (e.g. beaks), and crustaceans (e.g. carapace and appendages) found in fecal and regurgitate samples were identified in a variety of ways. Fish, cephalopods, and crustaceans were identified using a reference collection of fish skeletons, cephalopod beaks, and crustacean carapaces housed at Bishop Museum, Honolulu, Hawaii. Fish prey identification was also facilitated using reference atlases (i.e. Clarke 1986) and a multiple-access key (http://hbs.bishopmuseum.org/frc/, accessed on 5 November 2012). Cephalopod identifications were confirmed by experts (R. Young pers. comm. 24 July 2009). All prey remains were identified to family and, whenever possible, to genus and species. 


\section{Diet assessment}

We used several indices to evaluate the importance of each prey type in the diet of Hawaiian monk seals, including minimum number of individuals (MNI), frequency of occurrence (FO), percent frequency of occurrence (\%FO), numerical abundance (NA), and percent numerical abundance (\%NA). The MNI was determined for each taxon identified in each sample. The structures recovered from a single taxon were grouped together by type (e.g. individual jaw and skull bones, vertebrae, and scales). All scales recovered for a taxon were combined and counted as a single individual. Paired structures were enumerated using the formula from Chaplin (1971): $\mathrm{MNI}=L+R-$ $P_{i}$ where $L$ equals the number of left structures, $R$ equals the number of right structures, and $P$ is the number of pairs (e.g. jaw bones of the left and right sides are present and appear to be the same size or were still connected). Unpaired structures (e.g. parasphenoid, supraoccipital) were counted as a single individual. MNI was assigned based on the structure that yielded the largest estimate. Crustacean remains were the exception; because remains were most always fragmented, all crustacean parts were counted as 1 individual.

The FO is the number of samples in which a prey taxon was found. The \%FO of a prey taxon is FO divided by the total number of samples analyzed, multiplied by 100 . NA is the sum total of all MNI estimates for a prey taxon across all samples. The \%NA of a prey taxon was calculated as NA divided by the total number of individual prey identified in all samples, multiplied by 100 .

\section{Overlap between MHI and NWHI diets}

We used specific overlap (SO) as defined by Petraitis (1985) and modified by Ludwig \& Reynolds (1988) to assess overlap in the diet between the MHI and NWHI seals; SO indicates the likelihood that one resource utilization curve is a subset of another, not the more common evaluation of whether one envelopes another (e.g. Levins 1968). SO values range from 0 (i.e. no overlap) to 1 (i.e. complete overlap), with higher values indicating the probability that one resource utilization curve could have been randomly drawn from another. SO values vary if overlap is asymmetrical and can be statistically tested to evaluate whether overlap is complete; however, the test statistic $(U)$ cannot distinguish between some (potentially high) and no overlap.
We compared the MHI diet (present study) to results of 2 NWHI studies: Goodman-Lowe (1998) studied diet throughout the NWHI and M. Wong (unpubl. data) studied diet at French Frigate Shoals from 1995 to 2007. SO was designed to evaluate inter-specific overlap; however, we used the index to evaluate geographic differences for a single species. Further, SO was developed to examine proportional use of resources $(p)$ based on numerical abundance data. However, Goodman-Lowe (1998) presented only FO data. In comparisons with Goodman-Lowe's data, for each location we calculated $p$ for a prey item $i$ by dividing the frequency of occurrence $(F)$ of that prey item by the sum of all FO values at that location, where $r$ is the total of resource classes:

$$
p_{i}=\frac{F_{i}}{\sum_{i}^{r} F_{i}}
$$

Because $\mathrm{SO}$ is calculated with logarithms, no resource can have a zero (i.e. not exploited) value. In both overlap comparisons, prey items occurring in only 1 data set were assigned a proportion of $1 \times 10^{-8}$ in the other data set. This permitted the use of all exploited resources in overlap calculations without significantly changing $\mathrm{SO}$ values.

Last, to test the hypothesis that specific overlap of diet among locations was equal, we used the loglikelihood ratio, $W$ :

$$
W=\ln \left(\mathrm{SO}_{1,2} / \mathrm{SO}_{1,3}\right)
$$

If $W>2$, the null hypothesis is rejected; specific overlap of diet at Location 1 with diet at Location 2 is greater than the overlap of diet at Location 1 with diet at Location 3.

\section{RESULTS}

\section{Estimated composition of MHI monk seal diet}

We analyzed a total of 113 fecal and 7 regurgitate samples from a wide range of age classes of monk seals (4 weanlings, 15 juveniles, 68 adults, and 33 unknown age), and comprised of 34 males, 49 females, and 37 individuals of unknown sex. Of these samples, 11 (9.2\% FO) contained no prey remains. Unidentifiable prey remains occurred in $49.2 \%$ of samples.

Identified monk seal prey consisted of 20 fish families, at least 3 species of cephalopod, and 1 identified crustacean. The most frequently consumed fish families ranked in order of \%FO found in the MHI seal 
diet were Balistidae (48.3), Acanthuridae (32.5), Muraenidae (30.8), Serranidae (20.8), Holocentridae (17.5), Labridae (16.7), Scaridae (10.8), Ostraciidae (8.3), Monacanthidae (7.5), Scorpaenidae (6.7), and Congridae (6.7). Nine other fish families had $<5 \%$ FO (Fig. 2). Numerically (\%NA), the seal diet was dominated by Serranidae (88.5), followed by Balistidae (1.6), Muraenidae (1.4), and Acanthuridae (1.2). $\%$ NA values of other fish taxa were $<0.8 \%$ (Fig. 2).

Cephalopods were combined as a group for comparison with fish prey because the \%FO of Octopus spp. and squid were small. Cephalopods were found in $18.3 \%$ of samples (Fig. 2). Octopus cyanea was the most commonly occurring species (10\% FO), followed by $O$. ornatus (5\% FO). Squid (order Teuthoidea) occurred with $2.5 \%$ FO, but could not be identified to species level. Numerical abundance of these species mirrored the \%FO rankings, with $O$. cyanea being the most abundant $(0.4 \% \mathrm{NA})$, followed by $O$. ornatus $(0.2 \% \mathrm{NA})$, and squid $(0.1 \% \mathrm{NA})$.

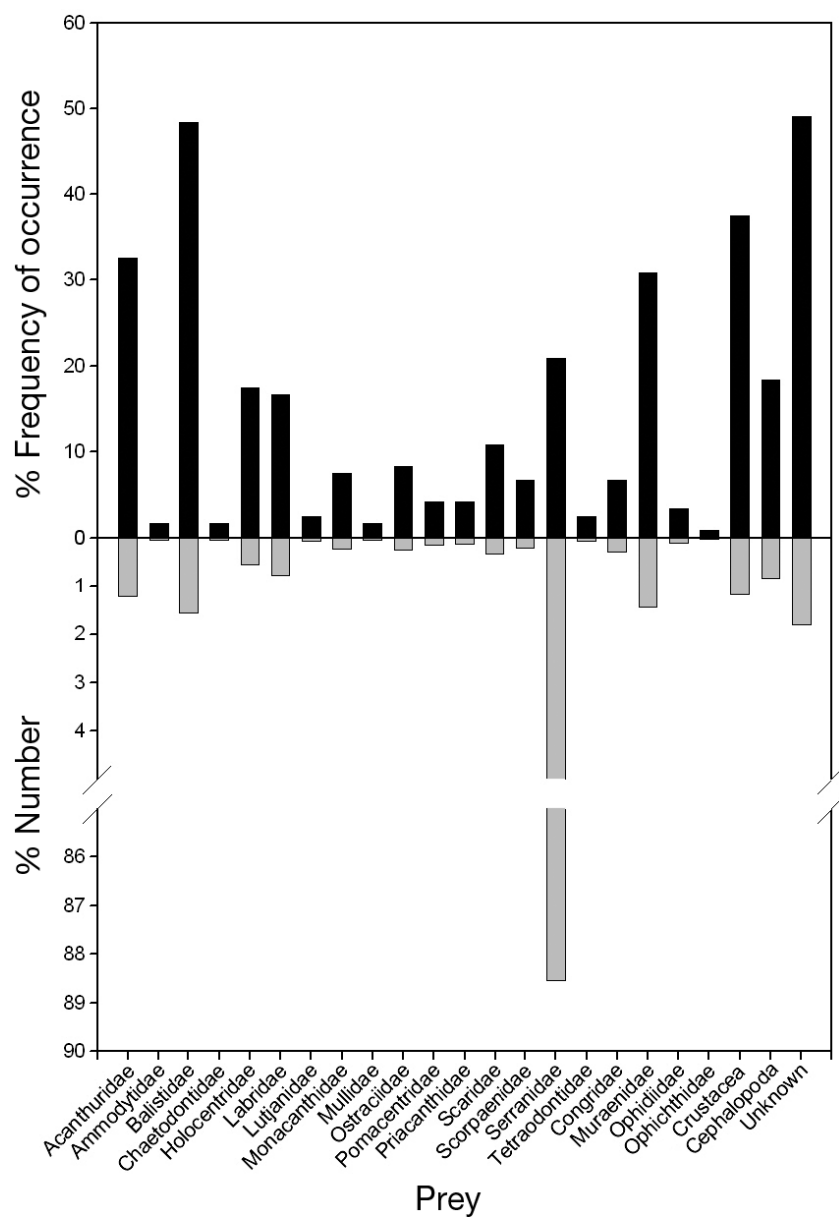

Fig. 2. Percent frequency of occurrence and percent numerical abundance of prey items identified to family level in the main Hawaiian Island monk seal Monachus schauinslandi diet
Crustaceans as a group occurred in $37.5 \%$ of samples (Fig. 2). However, crustacean parts were highly degraded and fragmented; thus, species identifications were not possible. The exceptions were 2 regurgitate samples containing freshwater prawn of the genus Macrobrachium (1.7\% FO, $0.05 \%$ NA).

Higher resolution taxonomic identifications were possible for 6 of 20 fish and 2 of 3 cephalopod families identified, as well as 1 crustacean family (Table 1). Not all prey remains were identified to the species level because they were either too degraded to identify or representative specimens were not part of the reference collection.

\section{Differences in prey composition between MHI and NWHI populations}

Twenty fish families were identified in the $\mathrm{MHI}$ diet when making a comparison with the NWHI diets by Goodman-Lowe (1998; $\mathrm{n}=31$ ) and $\mathrm{M}$. Wong (unpubl. data; $\mathrm{n}=36$ ). Two fish families (Ammodytidae and Ophidiidae) found in the MHI diet were not identified in the 1998 NWHI study, whereas all prey in the MHI diet were identified in the unpublished study. However, a total of 12 and 16 fish families (by Goodman-Lowe 1998 and M. Wong unpubl. data, respectively) were identified in the NWHI diet, but not in the MHI diet. Out of all the prey identified in the present study, fish prey accounted for $97.9 \%$ of the MHI diet, followed by crustaceans (1.2\%), and cephalopods $(0.9 \%)$. On the other hand, fish prey accounted for $78.6 \%$ of the 1998 NWHI diet, followed by cephalopods $(15.7 \%)$, and crustaceans $(5.7 \%)$. In the unpublished analysis of NWHI, diet consisted of

Table 1. Species identifications for 6 families and 2 invertebrate taxa in the main Hawaiian Island monk seal Monachus schauinslandi diet. Percent value reflects the percentage of the lower taxon within each family. MNI: minimum number of individuals of an identified species

\begin{tabular}{|lccc|}
\hline \multirow{2}{*}{ Family or taxon } & Higher taxon & Percent & MNI \\
\hline Acanthuridae & Naso & 8.5 & 4 \\
Labridae & Iniistius pavo & 3.3 & 1 \\
Monacanthidae & Aluterus Scriptus & 11.1 & 1 \\
Serranidae & $\quad$ Anthiinae & 99.6 & 3373 \\
Congridae & Ariosoma marginatum & 27.3 & 3 \\
Muraenidae & Gymnomuraena zebra & 1.8 & 1 \\
& Gymnothorax ypsilon & 1.8 & 1 \\
Crustacea & Gymnothorax prismodon & 9.1 & 5 \\
Cephalopoda & Macrobrachium spp. & 4.4 & 2 \\
& Octopus cyanea & 48.6 & 17 \\
& Octopus ornatus & 22.9 & 8 \\
\hline
\end{tabular}


$84.6 \%$ fish prey, followed by cephalopods (11\%), and crustaceans $(4.3 \%)$.

\section{Specific niche overlap indices}

SO values based on frequency of occurrence data are presented in Table 2. Overlap of the MHI diet with either NWHI diet is higher $($ mean $=0.545)$ than either NWHI diet with the MHI diet (mean $=0.235)$. Overlap between the 2 NWHI diets was similar (mean $=0.535)$. SO values based on numerical abundance data had lower absolute but the same relative values generated from frequency of occurrence data; overlap of the MHI diet with the recent NWHI diet (M. Wong unpubl. data) was 0.49 , whereas overlap of the NWHI diet (M. Wong unpubl. data) with the MHI diet was 0.19 . The test statistic, $U$, indicates that none of the above SO values represent complete overlap.

The log-likelihood ratios $(W)$ calculated with SO values based on frequency of occurrence data indicate that the MHI diet has significantly greater overlap with the recent NWHI diet (M. Wong unpubl. data) than the older NWHI diet (Goodman-Lowe 1998). However, both NWHI diets overlapped each other significantly more than the MHI diet.

On the basis of frequency of occurrence data, higher proportions of serranids, crustaceans, and balistids in the MHI diet were most responsible for incomplete overlap with the older (Goodman-Lowe 1998) NWHI diet. On the other hand, the presence of kyphosids, synodontids, and pomacanthids in the older NWHI diet were most responsible for incomplete overlap with the MHI diet; all of these fishes were absent in the MHI diet. The older NWHI diet also had a higher proportion of cephalopods, diminishing the degree of overlap. Differences most responsible for

Table 2. Comparison of specific overlap for frequency of occurrence data from: the main Hawaiian Islands (MHI; present study), northwestern Hawaiian Islands (NWHI; Goodman-Lowe 1998), and NWHI (M. Wong unpubl. data). Values indicate overlap of monk seal Monachus schauinslandi diet from column headings with diet from row headings. $0=$ no overlap; $1=$ complete overlap

\begin{tabular}{|lccc|}
\hline & MHI & $\begin{array}{c}\text { NWHI } \\
\text { (Goodman- } \\
\text { Lowe 1998) }\end{array}$ & $\begin{array}{c}\text { NWHI } \\
\text { (M. Wong } \\
\text { unpubl.) }\end{array}$ \\
\hline MHI & 1 & 0.21 & 0.26 \\
$\begin{array}{l}\text { NWHI (Goodman- } \\
\text { Lowe 1998) }\end{array}$ & 0.42 & 1 & 0.49 \\
NWHI (M. Wong unpubl.) & 0.67 & 0.58 & 1 \\
\hline
\end{tabular}

incomplete overlap of the MHI diet with the recent NWHI diet (M. Wong unpubl. data) were a higher proportion of serranids and lower proportions of acanthurids and balistids in the MHI diet. On the other hand, the presence of apogonids, kyphosids, and pomacanthids in the recent NWHI diet were most responsible for incomplete overlap with the MHI diet; all of these fishes were absent in the MHI diet.

On the basis of numerical abundance data, higher proportions of serranids, monacanthids, and scorpaenids in the MHI diet were most responsible for incomplete overlap with the recent NWHI diet (M. Wong unpubl. data). On the other hand, a higher proportion of labrids, congrids, and cephalopods in the NWHI diet and the presence of apogonids (absent from the MHI diet) were most responsible for incomplete overlap with the NHI diet.

\section{DISCUSSION}

\section{Methodology bias}

Inferring diet from diagnostic remains in feces and regurgitates is potentially subject to a number of biases that must be acknowledged before interpreting results. Some biases may be related to the freshness of sample leading to degradation or loss of samples, which is dependent on the length of time from defecation to collection (McIntosh et al. 2006); differential digestion, recovery, and identification of prey hard parts contributing to the apparent importance of certain prey in the diet (Gales \& Cheal 1992, Tollit et al. 2003); or passage rate time over-emphasizing the relative importance of prey consumed late in the foraging trip or near-shore species.

In this study the opportunistic collection of both fresh and old samples could have led to bias such that old samples may have been decomposed, degraded or scavenged, or dried out and scattered, or may have become more contaminated with substrate (e.g. broken shells that could be mistaken for prey) over time (McIntosh et al. 2006). Given the relative rarity of monk seals in the MHI and thus limited samples, it was necessary to utilize all samples collected. Most fecal and regurgitate samples were, however, collected from areas that are regularly surveyed by researchers or a volunteer network. Thus, it is likely that most samples were $<1$ wk old, diminishing the likelihood of sample loss.

Despite the aforementioned shortcomings, the use of prey hard parts in the present study has provided novel information necessary to understanding monk 
seals in the MHI and is supported by the results which are consistent with historical dietary analysis and video-based observations of foraging (Rice 1964, MacDonald 1982, Goodman-Lowe 1998, Parrish et al. 2000, 2005, 2008, Longenecker et al. 2006). Furthermore, it can be assumed that most biases operate equally in both regions, thus making the comparison of diet between the NWHI and MHI valid.

\section{Diet of MHI seals}

The diet of the Hawaiian monk seal in the MHI was diverse, consisting of at least 20 fish families, 3 species of cephalopod, and crustaceans. However, representatives of just 7 families dominated the MHI diet with $\geq 10 \%$ FO each. In order of greatest percent frequency of occurrence were balistids (triggerfishes), acanthurids (surgeonfishes), muraenids (moray eels), serranids (groupers and their allies), holocentrids (soldierfishes and squirrelfishes), labrids (wrasses), and scarids (parrotfishes).

Cephalopod prey occurred in $18.3 \%$ of the samples analyzed. The 2 most important species in the diet were Octopus cyanea and O. ornatus. Squid, from the order Teuthoidea, were also present in the diet, but in low numbers.

Crustacean remains were highly degraded in fecal samples, and no identifications were made, whereas crustacean remains could be identified from 2 regurgitate samples. These samples were collected near a river mouth on the island of Hawaii from a weaned monk seal and contained prawn claws. It is difficult to conclusively state the importance of crustaceans in the monk seal diet because many crustaceans found in the samples could be secondary prey items consumed by fish or cephalopods or contamination from beach substrate when the sample was collected. Future studies should employ other techniques such as DNA analysis (Deagle et al. 2005, Casper et al. 2007) to ultimately determine the importance and species composition of crustaceans as part of the Hawaiian monk seal diet.

\section{Seal habitat use based on species-level prey identification}

Six fish and 2 cephalopod prey were identified to species level (Table 1). These species identifications give some indication of the wide range of habitat MHI monk seals exploit. Some prey species inhabit a large habitat range, from shallow to deep water (Iniistius pavo, 8 to $100 \mathrm{~m}$ [Uchida \& Uchiyama 1986]; Aluterus scriptus, 1 to $120 \mathrm{~m}$ [Uchida \& Uchiyama 1986]; Ariosoma marginatum, 1.5 to $490 \mathrm{~m}$ [Uchida \& Uchiyama 1986]). Of the eel species, habitats range from shallow (Gymnomuraena zebra, 3 to $15 \mathrm{~m}$ [Böhlke \& Randall $2000]$ ), to mid-range (Gymnothorax prismodon, 38 to $44 \mathrm{~m}$ [Böhlke \& Randall 2000]), to deep (Gymnothorax ypsilon, 150 to $185 \mathrm{~m}$ [Böhlke \& Randall 2000]). The cephalopod species Octopus cyanea ranges from 1 to $60 \mathrm{~m}$ (Van Heukelem 1983) on coral reefs, and the habitat of $O$. ornatus is characterized as coastal or reef flats (K. Longenecker pers. obs., 12 May 2011). The 2 common Macrobrachium spp. in Hawaii are considered fresh- and brackish-water species whose habitat is mainly estuaries and streams (Maciolek \& Timbol 1981, Eldredge \& Miller 1997). All species identified, except for Macrobrachium spp., inhabit benthic habitats consisting of coral reefs, sediment, or sand substrate. No pelagic or mid-water species were found in the diet. This is consistent with previous findings from the NWHI that monk seals feed on benthic and demersal prey (Goodman-Lowe 1998, Parrish et al. 2000, Stewart et al. 2006).

\section{Differences in prey composition between MHI and NWHI populations}

The MHI and NWHI monk seal diets are similar in that in both regions prey are varied and include benthic species from inshore and offshore habitats, and both diurnal and nocturnal species (Goodman-Lowe 1998). However, the diet differs with regards to prey variety and prevalence. Monk seal diet in the MHI is less diverse, with 20 families identified versus the NWHI diet consisting of 31 and 36 families (Goodman-Lowe 1998 and M. Wong unpubl. data, respectively). Overall, fish was the most consumed prey group in all diet studies. Cephalopods were more often present than crustaceans in both NWHI diets, and the reverse was true in the MHI. Ammodytidae and Ophidiidae were 2 families identified in the MHI diet and unpublished study, but were not identified in the Goodman-Lowe (1998) study. Conversely, 12 and 16 fish families in the NWHI diet (GoodmanLowe 1998 and M. Wong unpubl. data, respectively) were not identified in the MHI diet.

One explanation for the difference in diet composition between the MHI and NWHI could be related to differences in sample sizes. Although we accepted 120 samples as sufficient for this study based on models from other pinniped species (Trites \& Joy 2005), we have to take into account that multiple samples 
may have come from the same individuals and same locations and may limit the prey diversity observed. It is therefore possible that the greater diversity of prey in the NWHI is due to the greater extent of sampling there. However, a large number of samples from the NWHI may also include repeat samplings from the same individual.

Investigator differences and the quality of the reference collection may also influence the identification of prey, as variation in methodologies may exist. As previously mentioned, ammodytids were not identified in the previous NWHI diet study by Goodman-Lowe (1998), but were identified in the unpublished study and in the study by Longenecker (2010). In addition, 11 other prey families identified in recent NWHI diet studies (Longenecker 2010, M. Wong unpubl. data) were not observed in the Goodman-Lowe (1998) study.

All diet studies other than that by Goodman-Lowe (1998) employed the same methodology and used the same reference collections for prey identifications. The reference collection above is extensive and currently contains 756 fish specimens representing 75 families and 200 species of fish found in Hawaii and the Pacific. In addition to this collection, systematic literature and a digital photo database were used to facilitate identification of fish bones and scales. The latter tools were either not used or unavailable for the original 1998 diet study. Goodman-Lowe (1998) used both the author's private reference collection and a limited faunal reference collection, consisting of only 104 fish specimens representing 53 families and 88 species, for prey identification. Because of the difference in methods and tools used for identification of prey in the Goodman-Lowe (1998) study, any comparison between that and other studies is likely to include investigator differences. It is not likely that families were missed in the current study due to the extensive reference collection; thus, the lower family diversity observed in the MHI is not an artifact of having too few species to compare against. A more extensive reference collection would have only possibly increased, not decreased, the number of families identified in Goodman-Lowe (1998), so the differences in family richness should be considered a minimum.

\section{Specific overlap}

SO was developed for NA data, which was not available in the Goodman-Lowe (1998) NWHI data set. Thus, we somewhat misused the SO index by incorporating frequency of occurrence (FO) data. We were able to compare the results of SO based on NA and FO data, available in the MHI (present study) and recent NWHI (M. Wong unpubl. data) studies. We are encouraged that relative SO values were the same for both data sets. Thus, we feel that SO based on FO data led to an understanding of geographic differences in dietary overlap. The high overlap of the MHI diet with NWHI diets relative to the converse suggests the MHI diet is narrower than (or a subset of) the NWHI diet. That several prey items in the NWHI diets were not found in the MHI diet supports this assertion.

Overlap was not complete between any dietary data set. Also, both NWHI diets overlapped more with each other than with the MHI diet. This would be expected since the former were in the same geographic region. The amount of overlap between the 2 NWHI studies may or may not imply dietary changes over time. For example, ammodytids were not identified in the 1998 diet study, but they were present in the more recent NWHI and MHI dietary studies. This could be attributed either to a shift in the diet resulting from changes in prey abundance or investigator differences; both aspects require further investigation. The more recent NWHI (M. Wong unpubl. data) study exhibited more overlap with the MHI study than did the earlier NWHI (Goodman-Lowe 1998) study. This hints at potential investigator differences, as discussed previously, because both investigators from the MHI and Wong's NWHI studies used the same system for identification and utilized the same faunal reference collection.

The dietary difference between the MHI and NWHI can be visualized by looking at a graph of FO (Fig. 3). The taxa contributing to the difference in the MHI over the older NWHI (Goodman-Lowe 1998) diet were Serranidae, Crustacea, and Balistidae. A disproportionately high occurrence of Serranidae was noted in the MHI diet. Two possibilities exist for this high occurrence of Serranidae. First, it is possible that this prey was easily accessible to seals in the MHI in the reef-associated areas off ledges and is less prevalent in the NWHI. Second, the diagnostic prey remains (i.e. otolith, bones) from this fish are extremely small and initially difficult to identify, and, therefore, it is possible they were missed in the older 1998 NWHI study. The high occurrence of crustaceans in the diet could be due to more consumption or differences in methods of enumeration. In the MHI study, all crustacean remains were counted, even if they were unidentifiable, whereas the methods used to enumerate crustaceans in the NWHI study are unknown. This may have resulted in the higher occurrence of crustaceans in the MHI diet and may not al- 


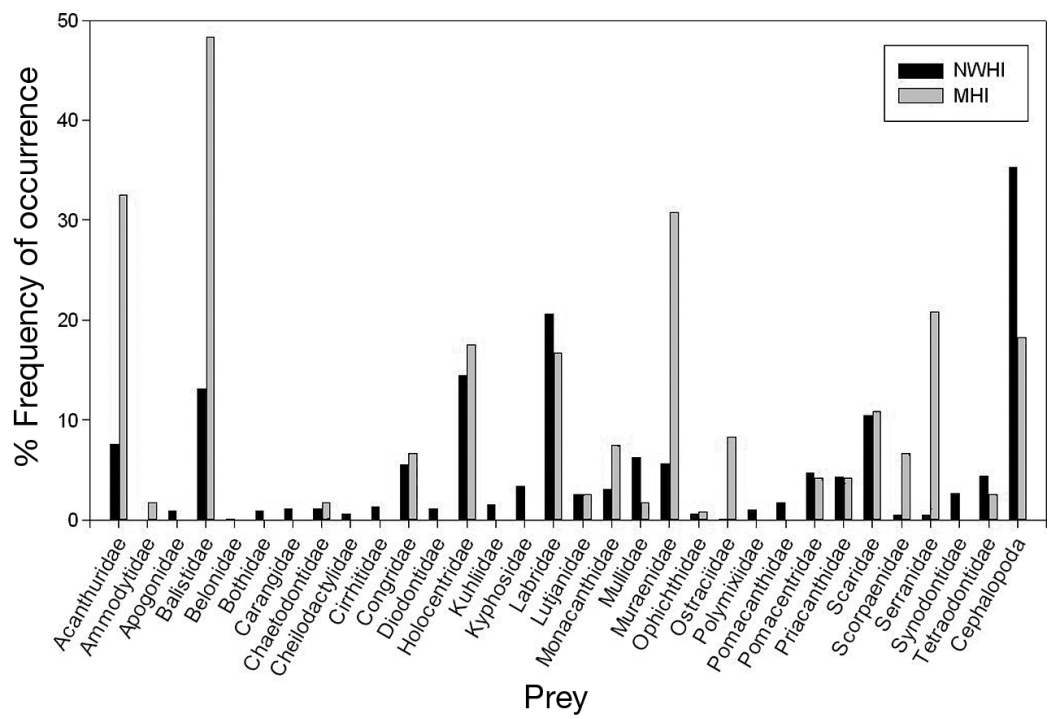

Fig. 3. Comparison of the percent frequency of occurrence of all prey families found in the diet of monk seals Monachus schauinslandi from the northwestern Hawaiian Islands (NWHI) study (Goodman-Lowe 1998) and the present study (main Hawaiian Islands, MHI)
The overall diet of the Hawaiian monk seal is diverse and consists of a wide range of families occupying an extensive range of habitats. Analyses indicate that, while there is considerable overlap in diets between regions, some differences do exist. Based on these findings we were unable to eliminate the possibility that diet differences may be a factor in observed differences in seal condition and population trends between regions. Findings from this study pose some interesting questions for further exploration.

The stark difference in diet diversity based on the number of prey taxa between the regions could imply 1 of 2 things. If resources are limited in the NWHI through competition or some other mechanism it would be expected that monk seals would diversify their diet through selecting different prey and/or utilizing different habitats that have a different species make-up. It would then be expected that given the low intra- and inter-specific competition in the MHI (Baker \& Johanos 2004, Parrish et al. 2008, Baker et al. 2011) seals may have a diet with lower diversity. Direct competition has been observed between monk seals and other apex predators in the NWHI, and it is believed that these interactions push monk seals to forage deeper or further away from their island haul-outs and utilize a variety of benthic habitats (e.g. sand, talus, coral reef, subphotic depths) (Parrish et al. 2000, 2005). Apex predator densities are far lower in the MHI, and preliminary tracking studies have indicated that they remain close to shore within the $200 \mathrm{~m}$ bathycontour line, rarely diving deep and that they have not been observed to travel far offshore to use seamounts (Littnan et al. 2006, Cahoon 2011).

An alternate explanation, if one assumes no prey preference or selectivity by seals, could be that differences in diet diversity reflect differences in species diversity between the regions. Data from fish surveys (fish $<15 \mathrm{~cm}$ total length and therefore likely to be consumed by monk seals) conducted in water between 0 and $30 \mathrm{~m}$ at FFS and the MHI demonstrated only moderate differences in the number of families observed on each survey. On average 6.2 families were identified for each dive at FFS, while 4.6 were identified at sites surveyed around the western MHI (National Marine Fisheries Service, NMFS are associated with coral reef habitats. 
unpubl. data). While there did appear to be greater family richness at FFS per dive, no families were found in the NWHI that were not represented in the MHI surveys (NMFS unpubl. data). These findings do not seem to support the idea that monk seals have a more diverse diet in the NWHI because of a different make-up of available prey families.

\section{CONCLUSIONS}

We were able to characterize the diet of MHI monk seals for the first time and compare them to other studies to explore whether differences in diet may help explain differing population trajectories or whether evidence indicated that other mechanisms were at play. While differences in diet occur between regions, they do not appear to be significant enough to completely explain the trends, thus lending support to the idea that MHI seals obtain similar prey with greater efficiency and therefore thrive compared to their NWHI conspecifics. A combination of factors that need to be explored may influence the ability of MHI seals to obtain prey with greater efficiency compared to those in the NWHI. The possibility of less intra- and inter-specific competition due to fewer seals and fewer apex predators in the MHI, is a viable hypothesis. MHI seals may not expend more energy than is necessary in searching and acquiring prey away from other seals and evading interactions with other apex predators like NWHI seals. Seals in the MHI may, therefore, achieve greater foraging efficiency, increasing their chances of survival. Another possibility is differences in type and quality of prey in the 2 locations; this was beyond the scope of the present study but should be taken into consideration in future analyses.

Though we have made progress in understanding the mechanisms that influence animal condition and population growth between these regions, more can be done to refine the comparison. Diet comparisons using quantitative fatty acids and genetics may help resolve issues when comparing diets at a genus or species level, thus helping to identify primary prey items more accurately and determine the energetic value of different prey resources. Foraging and energetic studies of both populations will also help distinguish whether a different amount of effort is being invested by seals to acquire food in each region. This information will be important to help manage and foster the continued population growth in the MHI and to seek feasible solutions to mitigate the chronic decline of seals in the NWHI.
Acknowledgements. We thank the NOAA Pacific Islands Fisheries Science Center (PIFSC) Hawaiian Monk Seal Research Program staff, and volunteers for providing samples. We acknowledge the Bishop Museum for providing laboratory space to process samples, and, specifically, A. Suzumoto for technical assistance and logistics. Thanks to M. Wong for providing data to use as comparison in this study, and R. Young for help in identifying cephalopod beaks. We thank J. Baker and 1 anonymous reviewer for their valuable comments which greatly improved this manuscript. Sample collection and research was conducted under NOAA MMPA/ESA Permit Number 10137.

\section{LITERATURE CITED}

Baker JD, Johanos TC (2004) Abundance of the Hawaiian monk seal in the main Hawaiian Islands. Biol Conserv 116:103-110

$>$ Baker JD, Harting AL, Wurth TA, Johanos TC (2011) Dramatic shifts in Hawaiian monk seal distribution and abundance are predicted to result from divergent regional trends. Mar Mamm Sci 27:78-93

Böhlke EB, Randall JR (2000) A review of the moral eels (Angulliformes: Muraenidae) of the Hawaiian Islands, with descriptions of two new species. Proc Acad Nat Sci Phila 50:203-278

Cahoon MK (2011) The foraging ecology of monk seals in the main Hawaiian Islands. MS, University of Hawaii at Manoa, Honolulu, HI

Carretta JV, Forney KA, Lowry MS, Barlow J and others (2010) U.S. Pacific marine mammal stock assessments: 2009. NOAA Tech Memo NOAA-TM-NMFS-SWFSC488

Casper RM, Jaman SN, Deagle BE, Gales NJ, Hindell M (2007) Detecting prey from DNA in predator scats: a comparison with morphological analysis, using Arctocephalus seals fed a known diet. J Exp Mar Biol Ecol 347: 144-154

Chaplin RE (1971) The study of animal bones from archaeological sites. Seminar Press, New York, NY

Clarke MR (1986) A handbook for the identification of cephalopod beaks. Clarendon, Oxford

Craig MP, Ragen TJ (1999) Body size, survival, and decline of juvenile Hawaiian monk seals, Monachus schauinslandi. Mar Mamm Sci 15:786-809

> Curtice C, Schick RS, Dunn DC, Halpin PN (2011) Home range analysis of Hawaiian monk seals (Monachus schauinslandi) based on colony, age, and sex. Aquat Mamm 37:360-371

> Deagle BE, Tollit DL, Jarman SN, Hindel MA, Trites AW, Gales NJ (2005) Molecular scatology as a tool to study diet: analysis of prey DNA in scats from captive Steller sea lions. Mol Ecol 14:1831-1842

Eldredge LG, Miller SE (1997) Numbers of Hawaiian species: Supplement 2, including a review of freshwater invertebrates. Records of the Hawaii Biological Survey for 1996. Bishop Mus Occas Pap 48:3-22

Friedlander AM, DeMartini EE (2002) Contrasts in density, size, and biomass of reef fishes between the northwestern and the main Hawaiian islands: the effects of fishing down apex predators. Mar Ecol Prog Ser 230:253-264

Gales NJ, Cheal AJ (1992) Estimating diet composition of the Australian sea-lion (Neophoca cinerea) from scat analysis: an unreliable technique. Wildl Res 19:447-456 
Goodman-Lowe GD (1998) Diet of the Hawaiian monk seal (Monachus schauinslandi) from the northwestern Hawaiian islands during 1991 to 1994. Mar Biol 132: 535-546

Iverson SJ, Stewart BS, Yochem PK (2010) Report on validation and calibration of fatty acid signatures in blubber as indicators of prey in Hawaiian monk seal diet. Admin Rep H-10-05, Pacific Islands Fish Fisheries Science Center, Honolulu, HI

Levins R (1968) Evolution in changing environments: some theoretical explorations. Princeton University Press, Princeton, NJ

Littnan CL, Stewart BS, Yochem PK, Braun R (2006) Survey for selected pathogens and evaluation of disease risk factors for endangered Hawaiian monk seals in the main Hawaiian islands. EcoHealth 3:232-244

Longenecker K (2010) Fishes in the Hawaiian monk seal diet, based on regurgitate samples collected in the Northwestern Hawaiian Islands. Mar Mamm Sci 26: 420-429

Ludwig JA, Reynolds JF (1988) Statistical ecology. John Wiley \& Sons, New York, NY

MacDonald CD (1982) Predation by Hawaiian monk seals on spiny lobsters. J Mammal 63:700

Maciolek JA, Timbol AS (1981) Environmental features and macrofauna of Kahana estuary, Oahu, Hawaii. Bull Mar Sci 31:712-722

McIntosh RR, Page B, Goldsworthy SD (2006) Dietary analysis of regurgitates and stomach samples from free-living Australian sea lions. Wildl Res 33:661-669

National Marine Fisheries Service (2010) Hawaiian monk seal field research manual. NOAA Fisheries, Honolulu, HI

Editorial responsibility: Simon Goldsworthy, West Beach, Australia
Parrish FA, Craig MP, Ragen TJ, Marshall GJ, Buhleier BM (2000) Identifying diurnal foraging habitat of endangered Hawaiian monk seals using a seal-mounted video camera. Mar Mamm Sci 16:392-412

Parrish FA, Marshall GJ, Littnan CL, Heithaus M and others (2005) Foraging of juvenile monk seals at French Frigate Shoals, Hawaii. Mar Mamm Sci 21:93-107

> Parrish FA, Marshall GJ, Bulheier BM, Antonelis GA (2008) Foraging interaction between monk seals and large predatory fish in the Northwestern Hawaiian Islands. Endang Species Res 4:299-308

> Petraitis PS (1985) The relationship between likelihood niche measures and replicated tests for goodness-of-fit. Ecology 66:1983-1985

Rice DW (1964) The Hawaiian monk seal: rare mammal survives in leeward islands. Nat Hist 73:45-55

Stewart BS, Antonelis GA, Baker JD, Yochem PK (2006) Foraging biogeography of Hawaiian monk seals in the northwestern Hawaiian islands. Atoll Res Bull 543: 131-145

Tollit DJ, Wong M, Winship AJ, Rosen DAS, Trites AW (2003) Quantifying errors associated with using prey skeletal structures from fecal samples to determine the diet of Stellar's sea lion (Eumetopias jubatus). Mar Mamm Sci 19:724-744

Trites AW, Joy R (2005) Dietary analysis from fecal samples: How many scats are enough? J Mammal 86:704-712

Uchida RN, Uchiyama JH (eds) (1986) Fishery atlas of the northwestern Hawaiian Islands. NOAA Tech Rep 38: $1-142$

Van Heukelem WF (1983) Octopus cyanea. In: Boyle PR (ed) Cephalopod life cycles, Vol I. Species accounts. Academic Press, San Francisco, CA, p 267-276

Submitted: August 7, 2012; Accepted: December 19, 2012 Proofs received from author(s): April 3, 2013 